\title{
Molecular Phylogeny of Suid Herpesvirus 1
}

\author{
Antônio A. Fonseca Jr., ${ }^{1}$ Érica B. Sales, ${ }^{2}$ Marcos B. Heinemann, ${ }^{2}$ and Jenner K. P. Reis ${ }^{2}$ \\ ${ }^{1}$ Laboratório de Biologia Molecular, Laboratório Nacional Agropecuário - Lanagro/MG, Ministério da Agricultura, \\ Pecuária e Abastecimento, Avenida Rômulo Joviano s/n, Fazenda Modelo, 33600-000 Pedro Leopoldo, MG, Brazil \\ ${ }^{2}$ Escola de Veterinária, Universidade Federal de Minas Gerais, Avenida Antônio Carlos, 6627, Pampulha, 31270-901 Belo Horizonte, \\ $M G$, Brazil \\ Correspondence should be addressed to Antônio A. Fonseca Jr.; antonio.fonseca@agricultura.gov.br
}

Received 12 September 2013; Accepted 8 January 2014; Published 10 April 2014

Academic Editors: M. Magnani, S. Pöhlmann, D. Shukla, and A. Vallinoto

Copyright (c) 2014 Antônio A. Fonseca Jr. et al. This is an open access article distributed under the Creative Commons Attribution License, which permits unrestricted use, distribution, and reproduction in any medium, provided the original work is properly cited.

Pseudorabies is a disease that significantly impacts the swine industry. This disease is caused by Suid Herpesvirus 1 (SuHV-1), which is a double-stranded DNA virus that belongs to the Herpesviridae family and the Alphaherpesvirinae subfamily and exhibits a slow rate of genetic evolution. The aim of this study was to use both full and partial sequences of SuHV-1 genes available in GenBank to examine the evolution and divergence of viruses isolated in different parts of the world. Partial and complete sequences of SuHV-1 genes were obtained either from GenBank (i.e., us6, us7, us8, us9, ul14, ul49.5, and ul44) or from genetic sequencing of Brazilian SuHV-1 samples. The results of this study corroborate previous phylogenetic studies of SuHV-1 that demonstrated different evolutionary profiles of isolates from different parts of the globe, with a rapid genetic dispersion of Chinese isolates. All of the phylogenetic trees generated in this study demonstrated a large genetic distance between SuHV-1 isolates from the Western and Eastern regions of the world.

\section{Introduction}

Pseudorabies (PR) is a disease that significantly impacts the swine industry. This disease is caused by Suid Herpesvirus 1 (SuHV-1), which is a double-stranded DNA virus that belongs to the Herpesviridae family and the Alphaherpesvirinae subfamily and exhibits a slow genetic evolution. The primary hosts of SuHV-1 are domestic or wild pigs (Sus scrofa). This disease also affects cows, dogs, and cats, but, in these species, the disease is fatal in nearly $100 \%$ of cases [1]. Although PR has been eradicated in domestic swine in many countries, such as the United States, Germany, and England, this disease still occurs in wild boars and other feral swine in these countries [2].

SuHV-1 has only one serotype and can be genetically typed using methods including whole genome enzymatic restriction with $\mathrm{BamHI}$, which demonstrates the presence of four genomic types [3, 4]. However, most recent publications also use partial sequences of the ul44 gene to evaluate the genetic variation of SuHV-1 isolates [5-8]. This gene encodes glycoprotein $\mathrm{C}(\mathrm{gC})$, which is a protein that is considered to be a potent inducer of the immune response and the principal component of adhesion to host cell receptors [9]. Phylogenetic analysis of partial sequences of ult4 separates SuHV-1 into five genotypes, with specific clades that include sequences derived from viruses isolated from domestic pigs or wild boars [10].

The $u s 8$ gene has also been used for phylogenetic analysis of SuHV-1 [6, 11, 12]. This gene is more conserved than ul44 but can also be used to detect genetic differences between SuHV-1 isolates from different regions. us 8 encodes glycoprotein $\mathrm{E}(\mathrm{gE})$. Although $\mathrm{gE}$ is not essential for viral replication, the absence of this protein reduces the virulence of the virus. us 8 is frequently deleted in attenuated SuHV-1 vaccine strains [13].

Sequences from other SuHV-1 genes are available in GenBank, but these genes are not used in studies of genetic variability. The herpesvirus genome is typically highly conserved [3] and even genes such as ul44 do not have sufficient variability to generate high-resolution phylogenetic trees [58]. Other genes could also be used, and some genes that are involved in envelope formation could contain enough 
TABLE 1: Genetic regions used in this work.

\begin{tabular}{|c|c|c|c|c|c|c|}
\hline Gene & Protein & Function & Type & Quantity & Size (base pairs) ${ }^{*}$ & Position* \\
\hline ul44 & $\mathrm{gC}$ & Cellular adhesion & Complete & 24 & 1443 & $53019-54461$ \\
\hline us6 & $\mathrm{gD}$ & Binding to surface receptors & Complete & 16 & 1197 & $118873-120075$ \\
\hline \multirow{2}{*}{ us7 } & \multirow{2}{*}{ gI } & \multirow{2}{*}{ Cell to cell spread } & Complete & 9 & 1086 & $120111-121193$ \\
\hline & & & Partial & 10 & 676 & $120111-120786$ \\
\hline \multirow{2}{*}{ us 8} & \multirow{2}{*}{$\mathrm{gE}$} & \multirow{2}{*}{ Cell to cell spread } & Complete & 22 & 1734 & $121297-123030$ \\
\hline & & & Partial & 48 & 404 & $121945-122348$ \\
\hline us 9 & $11 \mathrm{kDa}$ & Axonal transport & Complete & 19 & 321 & $123088-123384$ \\
\hline ul14 & ul14 & Viral morphogenesis & Complete & 12 & 480 & $75946-76425$ \\
\hline ul49.5 & $\mathrm{gN}$ & Viral morphogenesis and membrane fusion & Complete & 22 & 297 & $8840-9136$ \\
\hline
\end{tabular}

${ }^{*}$ These data refer to the complete genome of the Kaplan strain (JF797218).

phylogenetic information to divide the virus into different groups and provide more information about the transmission and worldwide distribution of this virus [14].

This study aimed to use both full and partial sequences of SuHV-1 genes available in GenBank to examine the evolution and divergence of strains isolated in different parts of the world. We focused on alternative genes (i.e., us6, us7, us8, us9, ul14, and ul49.5) to the commonly used ul44 to verify the genetic divergence of SuHV-1 from the Occident to the Orient.

\section{Material and Methods}

2.1. Genetic Sequences. Partial and complete sequences of SuHV-1 genes were obtained from GenBank (Table 1) together with all available information related to host, year, and country of isolation $[6,8,11,12,15-17]$. The sequences were named as the denomination of the isolate in GenBank followed by a three-letter code to identify the country of origin: Germany (GER), Argentina (ARG), Austria (AUS), Brazil (BRA), China (CHI), North Korea (SKO), Slovakia (SLK), Spain (ESP), the United States (USA), Japan (JAP), Hungary (HUN), Northern Ireland (NIR), Malaysia (MAL), and Sweden (SWE).

2.2. PCR. The us9, ull4, and ul49.5 genes of Brazilian SuHV1 strains and the standard Shope strain were sequenced in our laboratory to facilitate comparison. Each $20 \mu \mathrm{L}$ reaction contained the following reagents: $8 \%$ DMSO, $200 \mathrm{mmol} / \mathrm{L}$ of DNTPs, $1 \mathrm{pmol} / \mu \mathrm{L}$ of each primer (Table 2), $1.5 \mathrm{mmol} \mathrm{MgCl}_{2}$, $0.2 \mathrm{U}$ of Jumpstart Taq (Sigma, USA), $4 \mu \mathrm{L}$ of Green GoTaq $5 \mathrm{x}$ buffer (Promega, USA), and $2 \mu \mathrm{L}$ of DNA. The thermocycler was programmed with the following steps and cycling times: $95^{\circ} \mathrm{C}$ for $5 \mathrm{~min}$, followed by 35 cycles of $95^{\circ} \mathrm{C}$ for $50 \mathrm{~s}, 57^{\circ} \mathrm{C}$ for $50 \mathrm{~s}$, and $72^{\circ} \mathrm{C}$ for $50 \mathrm{~s}$ and a final extension stage of $72^{\circ} \mathrm{C}$ for $5 \mathrm{~min}$. The results were visualized on $1.5 \%$ agarose gels stained with ethidium bromide after running for one hour at 100 volts. The PCR products were sequenced using ABI 3130 equipment (Lifetech, USA).

2.3. Phylogenetic Analysis. Phylogenetic analysis was performed according to sample complexity. We first reconstructed all trees using substitution model F81 and Neighbor
TABle 2: Primers used in this study for amplification of SuHV-1 genes us9, ull4 e ul49.5.

\begin{tabular}{lcc}
\hline Gene & \multicolumn{1}{c}{ Primer $\left(5^{\prime}-3^{\prime}\right)$} & Amplicon $(\mathrm{pb})$ \\
\hline \multirow{2}{*}{ s 9} & $\begin{array}{r}\text { F: GAGAAACCGGAAGTGACGAA } \\
\text { R: GGGGCCCATTTATTGTGAC }\end{array}$ & 550 \\
\hline \multirow{2}{*}{$u l 4$} & $\begin{array}{c}\text { F: GCGATGGCAAAGTTGAAAAA } \\
\text { R: GTCGAGGGTCGCGTACTG }\end{array}$ & 794 \\
\hline \multirow{2}{*}{$u l 49.5$} & $\begin{array}{c}\text { F: CCCAGGGGAACCTTATAAAATC } \\
\text { R: TTTCTCGAGCTGGACATGG }\end{array}$ & 447 \\
\hline
\end{tabular}

Joining. We then tested other evolutionary models that were selected using jModelTest software [18]. The models and software programs used in this study are presented in Table 3 $[19,20]$. All sequences were tested for positive selective pressure using Selecton software [21]. Because a large number of us 8 sequences are available, we used the programs of DNASP [22] and Network [23] for phylogenetic network analysis.

\section{Results}

Phylogenetic analysis of multiple sequences derived from different regions of the SuHV-1 genome generated trees with similar profiles; however, the $u s 6$ gene was an exception (Figures $1,2,3$, and 4). The primary characteristic observed was the formation of two clusters. Cluster 1 included sequences from the Occident and a small number of Asian samples, and Cluster 2 included exclusively sequences from countries in the East (i.e., China, Malaysia, Taiwan, and South Korea). The partial sequences of the us 8 gene generated a tree with a lower degree of differentiation. No differences in tree information were observed for the trees generated from the complete and partial sequences of $u s 7$. Some isolates, such as the Hungarian (i.e., Kaplan and Shope) and Brazilian sequences, clustered together in all trees. The Rice and Becker samples from the USA also exhibited similar profiles. The bootstrap values were low in most trees, except in cases such as Clusters 1 and 2.

The Asian SuHV-1 genome sequences presented two patterns. The first pattern was close to that of the Western samples and was distributed among different subgroups, close to a group of atypical strains that are most frequently 
TABLE 3: Substitution models, reconstruction of phylogenetic tree and programs used for each group of sequences studied in this work.

\begin{tabular}{|c|c|c|c|c|}
\hline Gene & Type & Evolutionary models & Phylogeny & Software \\
\hline ul44 & $\begin{array}{l}\text { Complete } \\
\text { Partial }\end{array}$ & GTR $\Gamma 4+\mathrm{I}$ & Bayesian Inference & Mr.Bayes $^{\mathrm{a}}$ \\
\hline us 6 & Complete & GTR & Maximum Likelihood & Seaview $^{\mathrm{b}}$ \\
\hline us7 & $\begin{array}{l}\text { Complete } \\
\text { Partial }\end{array}$ & $\mathrm{HKY}+\Gamma$ & Maximum Likelihood & Seaview \\
\hline us 8 & $\begin{array}{l}\text { Complete } \\
\text { Partial }\end{array}$ & $\begin{array}{c}\mathrm{GTR}+\Gamma \\
\mathrm{HKY}\end{array}$ & $\begin{array}{l}\text { Maximum Likelihood } \\
\text { Maximum Likelihood }\end{array}$ & $\begin{array}{l}\text { Seaview } \\
\text { Seaview }\end{array}$ \\
\hline us 9 & Complete & $\mathrm{F} 81$ & Neighbor Joining & Seaview \\
\hline ul14 & Complete & F81 & Neighbor Joining & Seaview \\
\hline ul49.5 & Complete & $\operatorname{TrN}$ & Neighbor Joining & Seaview \\
\hline
\end{tabular}

${ }^{\mathrm{a}}$ Huelsenbeck e Ronquist, $2001^{\mathrm{b}}$ Gouy et al., 2010 [20].

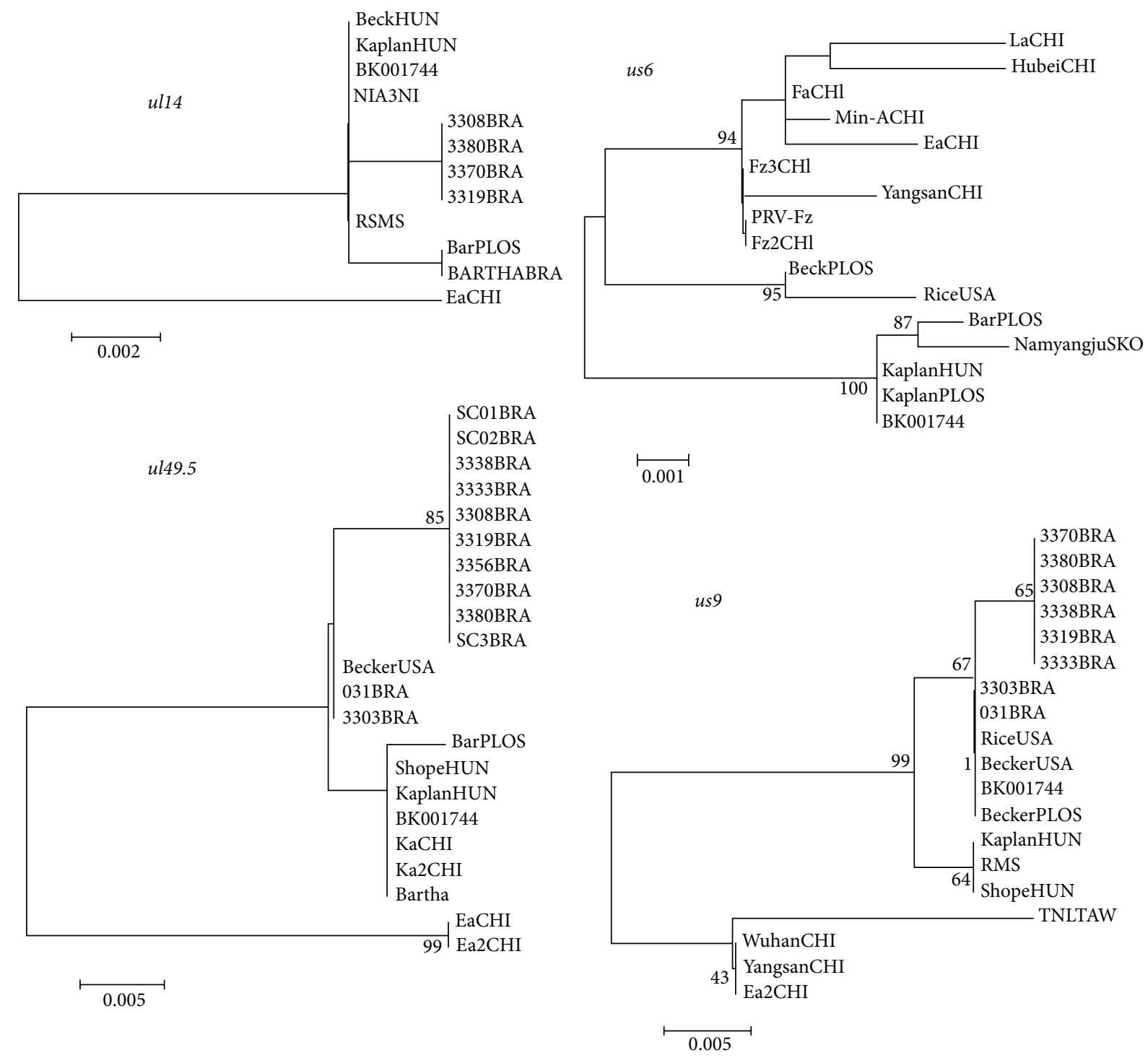

Figure 1: Phylogenetic trees for genes ul14, ul49.5, us6, and us9. The models used in the reconstruction of each tree are listed in Table 3. Only bootstrap values above 70 are shown. Topologies are similar with the exception from the one constructed from us6, indicating conflicting signals in the analysis. 

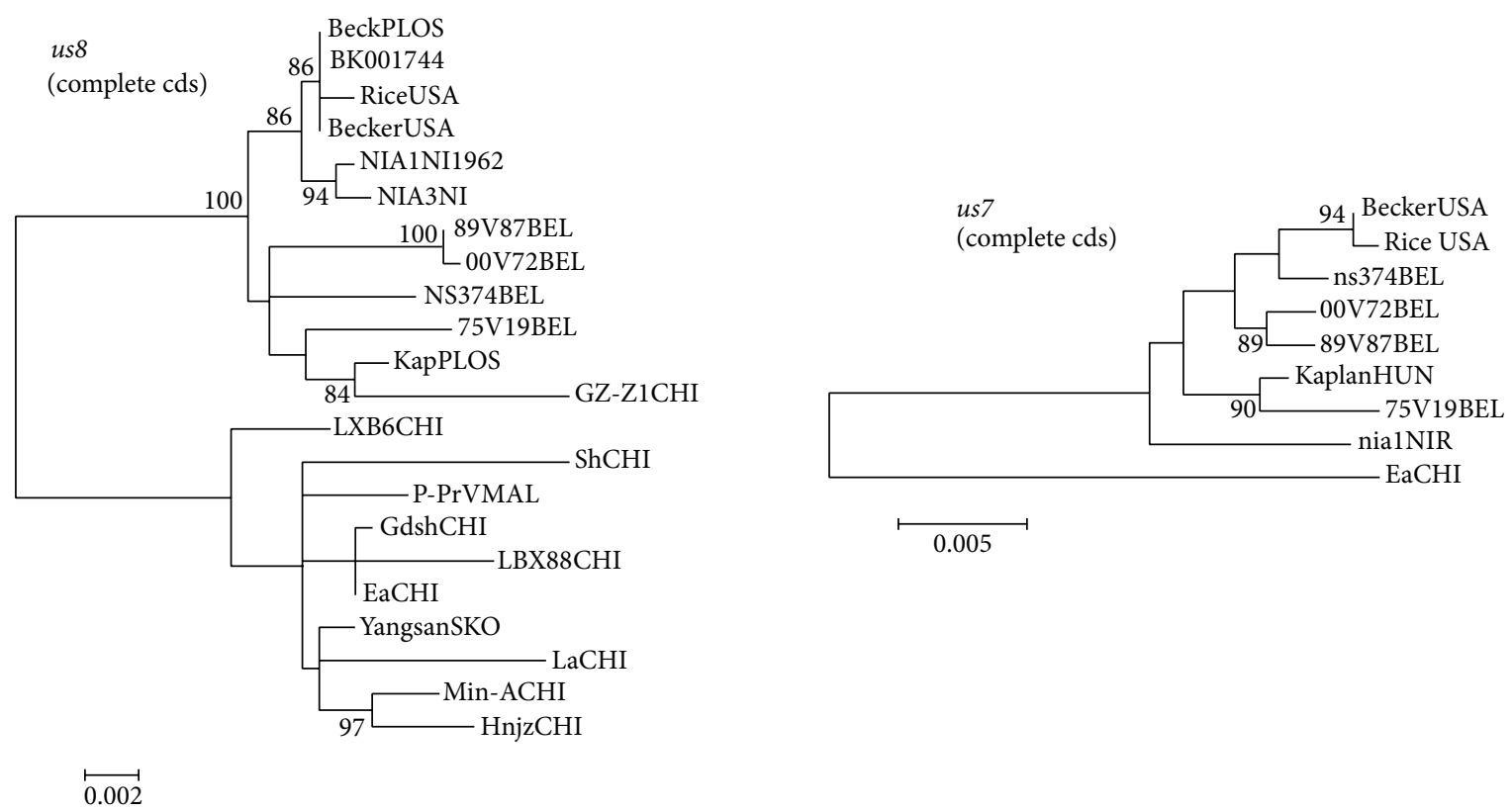

Figure 2: Phylogenetic trees for genes us7 and us8. The models used in the reconstruction of each tree are listed in Table 3. Only bootstrap values above 70 are shown.

found in Brazil but also occur in the USA and Europe. The second pattern is more distant and acts as a root for all trees reconstructed in this work, with the exception of $u s 6$. In both cases, the sequences of Asian origin exhibited a greater degree of genetic variation than sequences within other clades.

Phylogenetic analysis using only partial sequences of the us8 gene in DNAsp identified a total of 31 haplotypes; 23 of these haplotypes were formed exclusively by sequences from China. Only 11 polymorphic sites were observed in Western haplotypes (i.e., 5 singleton variable sites and 6 parsimony informative sites). In contrast, 53 polymorphic sites were observed in Eastern haplotypes (i.e., 38 singleton variable sites and 15 parsimony informative sites). The phylogenetic network demonstrated the divergence of these two main groups of SuHV-1 (Figure 5). Three main haplotypes form the base of the network. The first haplotype has a low frequency and is represented by a GenBank isolate named Kaplan, which is a strain that typically clusters with sequences derived from SuHV-1 isolates from wild boars. The other two groups occur more frequently. The Western cluster was formed by 15 sequences from Europe (i.e., Italy and Belgium), a single sequence from the USA, and a single sequence from Brazil. The Eastern cluster in the base of the network is formed by nine sequences from China and one sequence from South Korea.

\section{Discussion}

Molecular analyses to characterize SuHV-1 isolates are commonly performed using partial sequences of the ul44 gene [10]; other genes are rarely studied. The purpose of this study was to analyze partial and complete sequences of SuHV-1 genes available in GenBank. All of the phylogenetic trees generated in this study demonstrated a large genetic distance between strains isolated in the Western and Eastern regions of the globe.

SuHV-1 has only one serotype, but this virus can be classified into four genomic types by restriction enzyme digestion analysis of the complete genome [4]. This analysis requires large amounts of viral DNA and can be laborious and time consuming. For this reason, partial gene sequencing has been increasingly used to replace full genome sequencing analysis [5-8, 10-12]. Phylogenetic analysis of partial ul44 sequences demonstrated that SuHV-1 has a slow rate of genetic evolution and can be divided into five groups that are designated as A, B, C, D, and E [10]. Genetic groups A and $C$ are formed by strains isolated from outbreaks of PR related to feral pigs. Groups B and D are formed by strains isolated from outbreaks related to domestic pigs. Group E is the most genetically diverse group and includes strains from Eastern regions, primarily China. Phylogenetic analysis using complete sequences of $u l 44$ generated genetic groups similar to those described in previous studies that used only partial sequences $[10,12]$.

Phylogenetic analysis of sequences available in the GenBank revealed a deep genetic distance between Clusters 1 and 2. Cluster 1 was divided into at least two clades and was always separated from the Eastern SuHV-1 genomic sequences. The low genetic diversity of these isolates is consistent with the slow evolution of herpesviruses. In some cases, SuHV-1 strains exhibit the same genetic profile for up to twenty years in the same region $[6,8]$. The low genetic diversity of SuHV-1 is also responsible for the low bootstrap values observed in the trees constructed in this study and in previous studies $[5,7,8]$. The smaller size of the partial sequences of the $u s 8$ gene generated a tree with a lower degree of differentiation, 


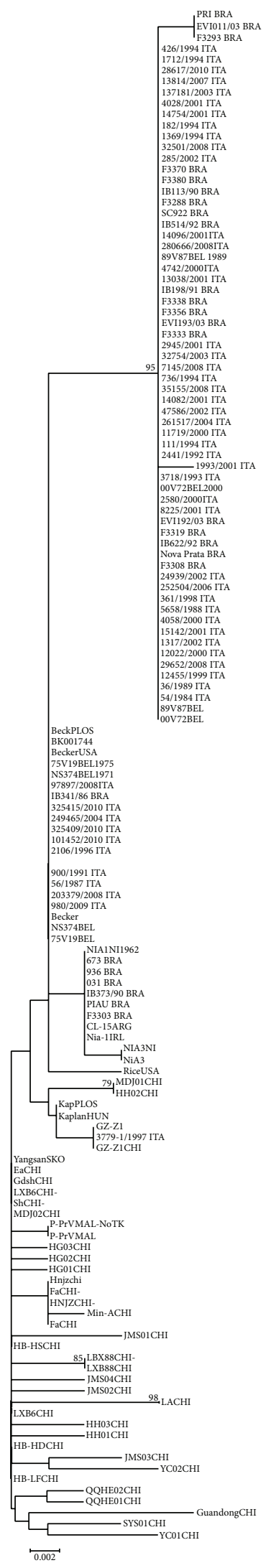

FIgURE 3: Phylogenetic trees for partial sequences of gene us8. The models used in the reconstruction of each tree are listed in Table 3. Only bootstrap values above 70 are shown.

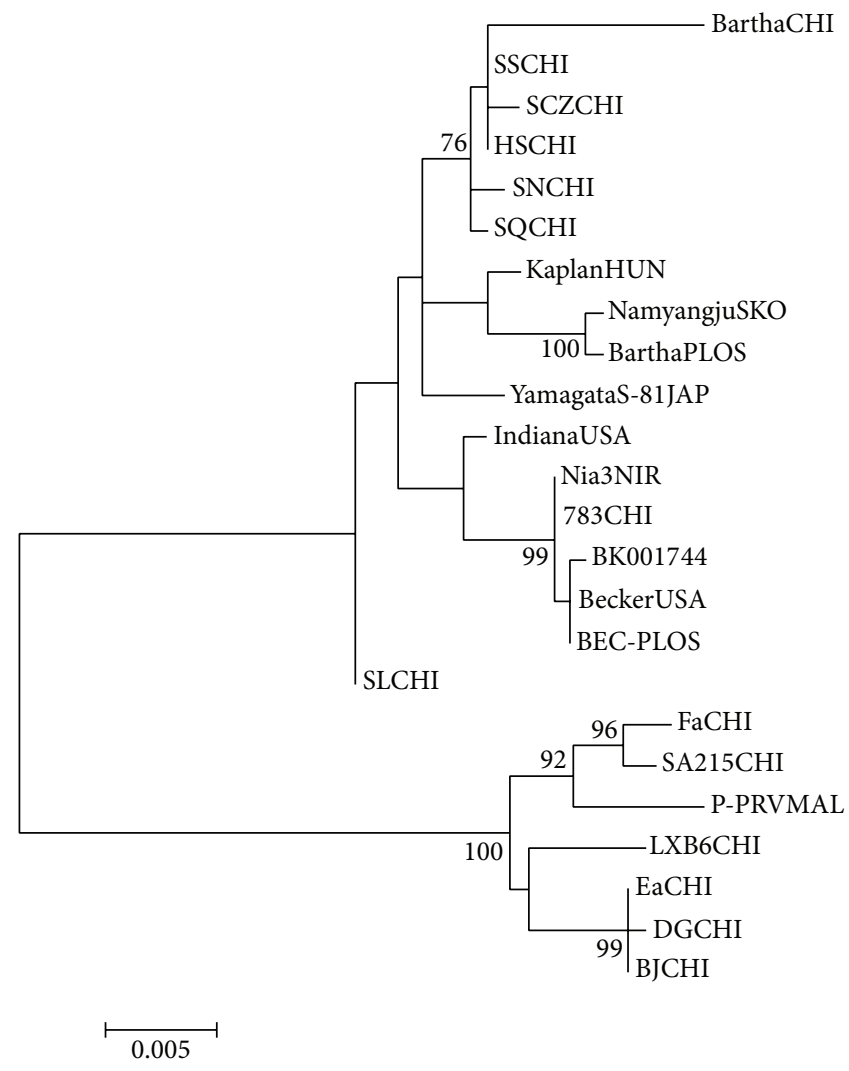

FIgure 4: Phylogenetic trees for complete sequences of the gene ul44. The complete sequences of ul44 groups showed similar groups to those found in trees reconstructed using partial ul44 sequences.

perhaps because most of the variability is located in the initial portion of the gene. Most of the partial sequences of the us 8 gene which are available in the Genbank are sequences from the middle portion of the gene, which is more conserved than the initial and terminal portions. Altogether, these data indicate that phylogenetic analyses performed using the complete gene or the most variable regions of the SuHV-1 genome may be more accurate.

Cluster 2 exhibited a characteristic genetic diversity. The high variability observed in the $u s 6, u s 8$, and $u l 44$ genes is not consistent with the evolution of SuHV-1 described in other studies [6-8]. Goldberg et al. [5] reported that SuHV1 isolates from outbreaks of PR that occurred in the USA in the state of Illinois in 1989 exhibited greater variability than isolates from other regions of the world. Nevertheless, the variability of these isolates was appreciably smaller than the genetic distance observed in Cluster 2 in this work.

SuHV-1 can infect many species, but pigs and wild boars are the principal hosts responsible for disease transmission [24]. Information available in the literature and in GenBank indicated the type of animals from which the viruses were isolated, but we could not find any correlation between clusters, genetic variability, and species (data not shown). Other studies reported differences between strains isolated from pigs and from wild boars $[10,12]$, but no specific viruses have been isolated from cows, dogs, or cats to date $[5,10]$. 


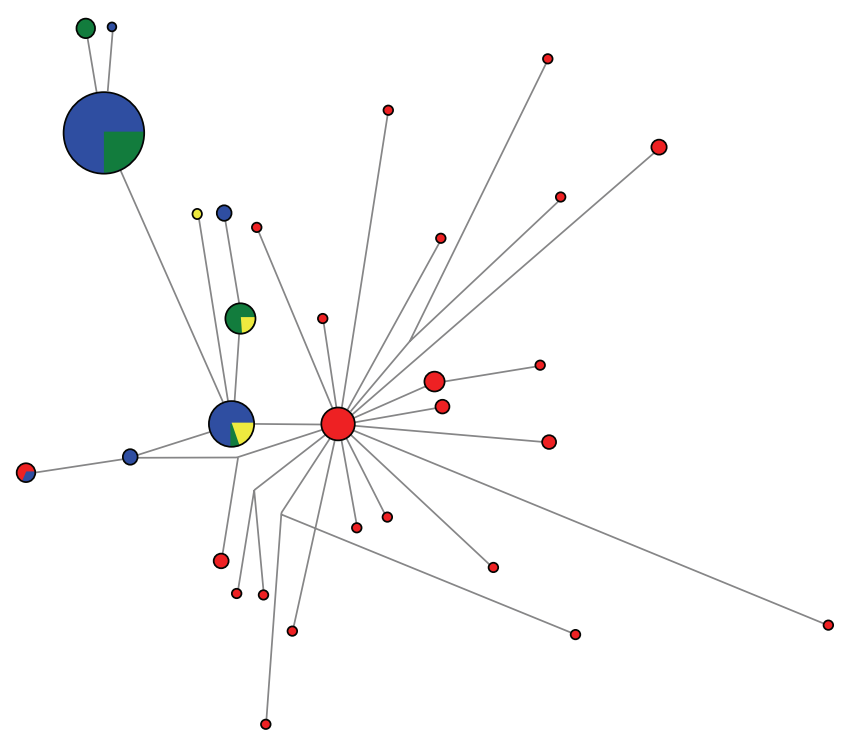

FIGURE 5: Phylogenetic network reconstructed using network from us 8 sequences of SuHV-1 isolates. Each circle is colored according to the number of sequences from different regions grouped in that haplotype. Red represents sequences from strains isolated in Asia, green from strains isolated in South America, yellow from strains isolated in USA, and blue from strains isolated in Europe. The base of the network is formed by three haplotypes. Western and Eastern sequences are connected by the two most frequent haplotypes present.

Most studies of SuHV-1 phylogeny are based only on reconstructed phylogenetic trees. We used phylogenetic networks to analyze genetic variability in partial us 8 sequences. Three haplotypes were found in the base of the network; one haplotype formed exclusively by sequences from Europe, another haplotype formed by sequences from Europe, the United States, and South America, and a third haplotype formed by sequences from China. The phylogenetic network generated in this study demonstrates a low dispersion of SuHV-1 in the Western part of the world and a rapid dispersion of SuHV-1 from a homogeneous group of samples to a higher frequency of haplotypes in China. Only the us 8 and ul44 genes exhibited evidence of positive selective pressure; thus, natural selection alone does not explain the genetic diversity of SuHV-1 isolates from China. The high genetic diversity of Cluster 2 may be associated with the high prevalence of SuHV-1 in China [25].

\section{Conclusion}

The results of this work corroborate other phylogenetic studies that demonstrated different evolutionary profiles of SuHV-1 isolates from the Eastern and the Western regions of the globe, with a rapid genetic dispersion of Chinese isolates.

\section{Conflict of Interests}

The authors declare that there is no conflict of interests regarding the publication of this paper.

\section{Acknowledgments}

The authors would like to thank FAPEMIG, INCT-Pecuária, and Lanagro/MG for financial support. Marcos B. Heinemann and Jenner K. P. Reis are CNPq fellowship recipients.

\section{References}

[1] L. E. Pomeranz, A. E. Reynolds, and C. J. Hengartner, "Molecular biology of pseudorabies virus: impact on neurovirology and veterinary medicine," Microbiology and Molecular Biology Reviews, vol. 69, no. 3, pp. 462-500, 2005.

[2] T. Müller, E. C. Hahn, F. Tottewitz et al., "Pseudorabies virus in wild swine: a global perspective," Archives of Virology, vol. 156, no. 10, pp. 1691-1705, 2011.

[3] L. S. Christensen, "The population biology of suid herpesvirus 1," APMIS Supplement, vol. 103, no. 48, pp. 1-48, 1995.

[4] A. A. Fonseca Jr., C. G. Magalhães, E. B. Sales et al., "Genotyping of the pseudorabies virus by multiplex PCR followed by restriction enzyme analysis," ISRN Microbiology, vol. 2011, Article ID 458294, 4 pages, 2011.

[5] T. L. Goldberg, R. M. Weigel, E. C. Hahn, and G. Scherba, "Comparative utility of restriction fragment length polymorphism analysis and gene sequencing to the molecular epidemiological investigation of a viral outbreak," Epidemiology and Infection, vol. 126, no. 3, pp. 415-424, 2001.

[6] A. A. Fonseca Jr., M. F. Camargos, A. M. de Oliveira et al., "Molecular epidemiology of Brazilian pseudorabies viral isolates," Veterinary Microbiology, vol. 141, no. 3-4, pp. 238-245, 2010.

[7] E. C. Hahn, B. Fadl-Alla, and C. A. Lichtensteiger, "Variation of Aujeszky's disease viruses in wild swine in USA," Veterinary Microbiology, vol. 143, no. 1, pp. 45-51, 2010.

[8] T. Müller, B. G. Klupp, C. Freuling et al., "Characterization of pseudorabies virus of wild boar origin from Europe," Epidemiology and Infection, vol. 138, no. 11, pp. 1590-1600, 2010.

[9] E. Trybala, T. Bergström, D. Spillmann, B. Svennerholm, S. J. Flynn, and P. Ryan, "Interaction between pseudorabies virus and heparin/heparan sulfate: pseudorabies virus mutants differ in their interaction with heparin/heparan sulfate when altered for specific glycoprotein C heparin-binding domain," The Journal of Biological Chemistry, vol. 273, no. 9, pp. 5047-5052, 1998.

[10] A. A. Fonseca Jr., M. L. Sales, M. B. Heinemann, R. C. Leite, and J. K. Reis, "Pseudorabies virus can be classified into five genotypes using partial sequences of ul44," Brazilian Journal of Microbiology, vol. 43, no. 4, pp. 1632-1640, 2012.

[11] A. Steinrigl, S. Revilla-Fernández, J. Kolodziejek et al., "Detection and molecular characterization of Suid herpesvirus type 1 in Austrian wild boar and hunting dogs," Veterinary Microbiology, vol. 157, no. 3-4, pp. 276-284, 2012.

[12] E. Sozzi, A. Moreno, D. Lelli et al., "Genomic characterization of pseudorabies virus strains isolated in Italy," Transboundary Emerging Diseases, 2013.

[13] W. A. M. Mulder, L. Jacobs, J. Priem et al., "Glycoprotein gEnegative pseudorabies virus has a reduced capability to infect second- and third-order neurons of the olfactory and trigeminal routes in the porcine central nervous system," Journal of General Virology, vol. 75, no. 11, pp. 3095-3106, 1994.

[14] A. A. Fonseca Jr., M. B. Heinemann, R. C. Leite, and J. K. P. Reis, "A comparative analysis of envelope and tegument proteins of suid herpesvirus 1, bovine herpesvirus 1 and bovine herpesvirus 5," Archives of Virology, vol. 155, no. 10, pp. 1687-1692, 2010. 
[15] K. Ishikawa, M. Tsutsui, K. Taguchi, A. Saitoh, and M. Muramatsu, "Sequence variation of the gC gene among pseudorabies virus strains," Veterinary Microbiology, vol. 49, no. 3-4, pp. 267272, 1996.

[16] S. Glorieux, H. W. Favoreel, G. Meesen, W. de vos, W. van den Broeck, and H. J. Nauwynck, "Different replication characteristics of historical pseudorabies virus strains in porcine respiratory nasal mucosa explants," Veterinary Microbiology, vol. 136, no. 3-4, pp. 341-346, 2009.

[17] M. S. Serena, G. E. Metz, E. C. Mórtola, and M. G. Echeverría, "Phylogenetic analysis of Suid herpesvirus 1 isolates from Argentina," Veterinary Microbiology, vol. 154, no. 1-2, pp. 78-85, 2011.

[18] D. Posada, "Selection of models of DNA evolution with jModelTest," Methods in Molecular Biology, vol. 537, pp. 93-112, 2009.

[19] F. Ronquist and J. P. Huelsenbeck, "MrBayes 3: Bayesian phylogenetic inference under mixed models," Bioinformatics, vol. 19, no. 12, pp. 1572-1574, 2003.

[20] M. Gouy, S. Guindon, and O. Gascuel, "Sea view version 4: a multiplatform graphical user interface for sequence alignment and phylogenetic tree building," Molecular Biology and Evolution, vol. 27, no. 2, pp. 221-224, 2010.

[21] A. Stern, A. Doron-Faigenboim, E. Erez, E. Martz, E. Bacharach, and T. Pupko, "Selecton 2007: advanced models for detecting positive and purifying selection using a Bayesian inference approach," Nucleic Acids Research, vol. 35, pp. W506-W511, 2007.

[22] P. Librado and J. Rozas, "DnaSP v5: a software for comprehensive analysis of DNA polymorphism data," Bioinformatics, vol. 25, no. 11, pp. 1451-1452, 2009.

[23] H. J. Bandelt, P. Forster, and A. Röhl, "Median-joining networks for inferring intraspecific phylogenies," Molecular Biology and Evolution, vol. 16, no. 1, pp. 37-48, 1999.

[24] A. A. Fonseca Jr., E. A. Costa, T. S. Oliveira et al., "PCR Multiplex para detecção dos principais herpesvírus neurológicos de ruminantes," Arquivo Brasileiro de Medicina Veterinária e Zootecnia, vol. 63, pp. 1405-1413, 2011.

[25] X. Wang, A. Dai, and X. Li, "Serological survey of infection by swine wild PRV in western Fujian Province," Journal of Anhui Agricultural University, vol. 4, pp. 450-543, 2008. 

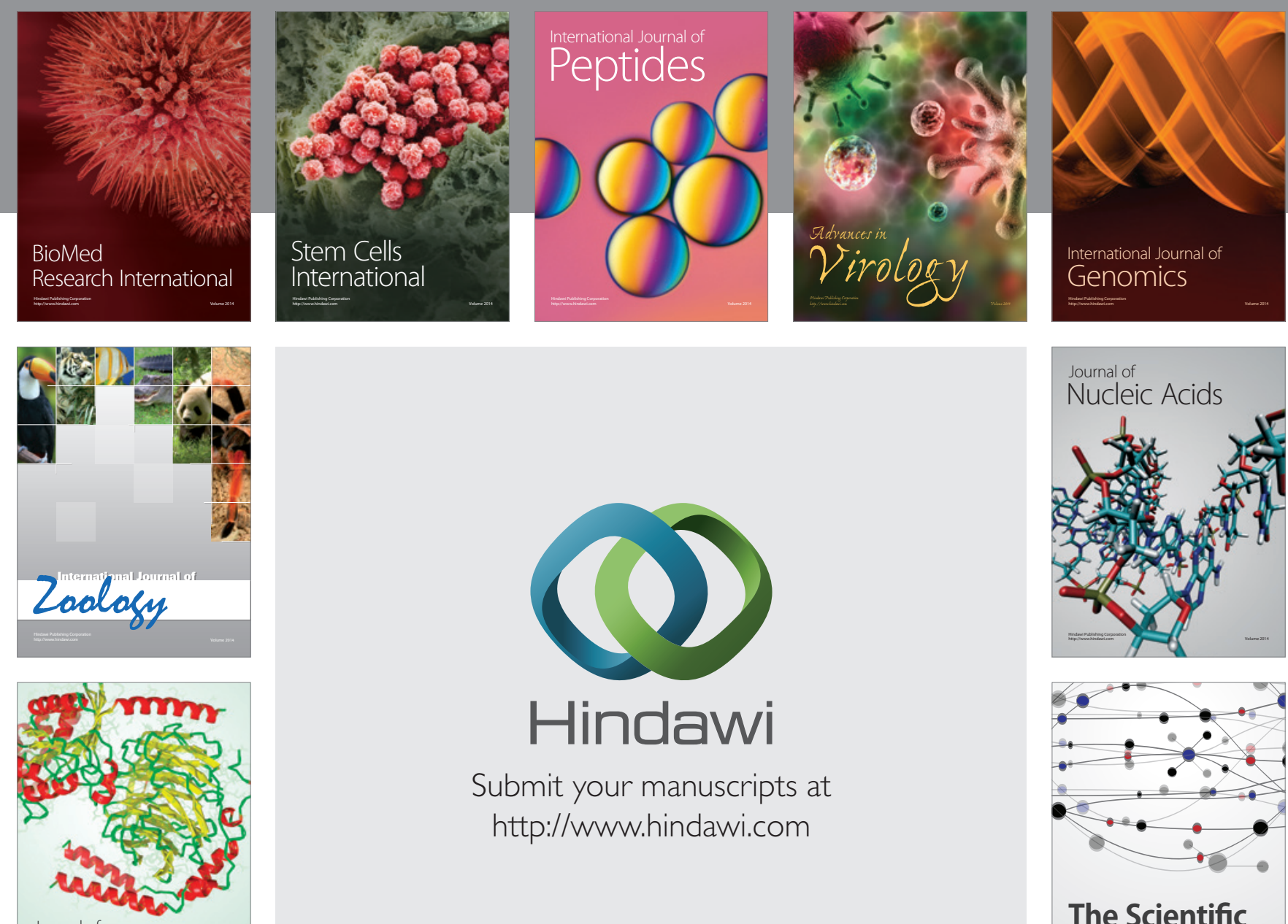

Submit your manuscripts at

http://www.hindawi.com

Journal of
Signal Transduction
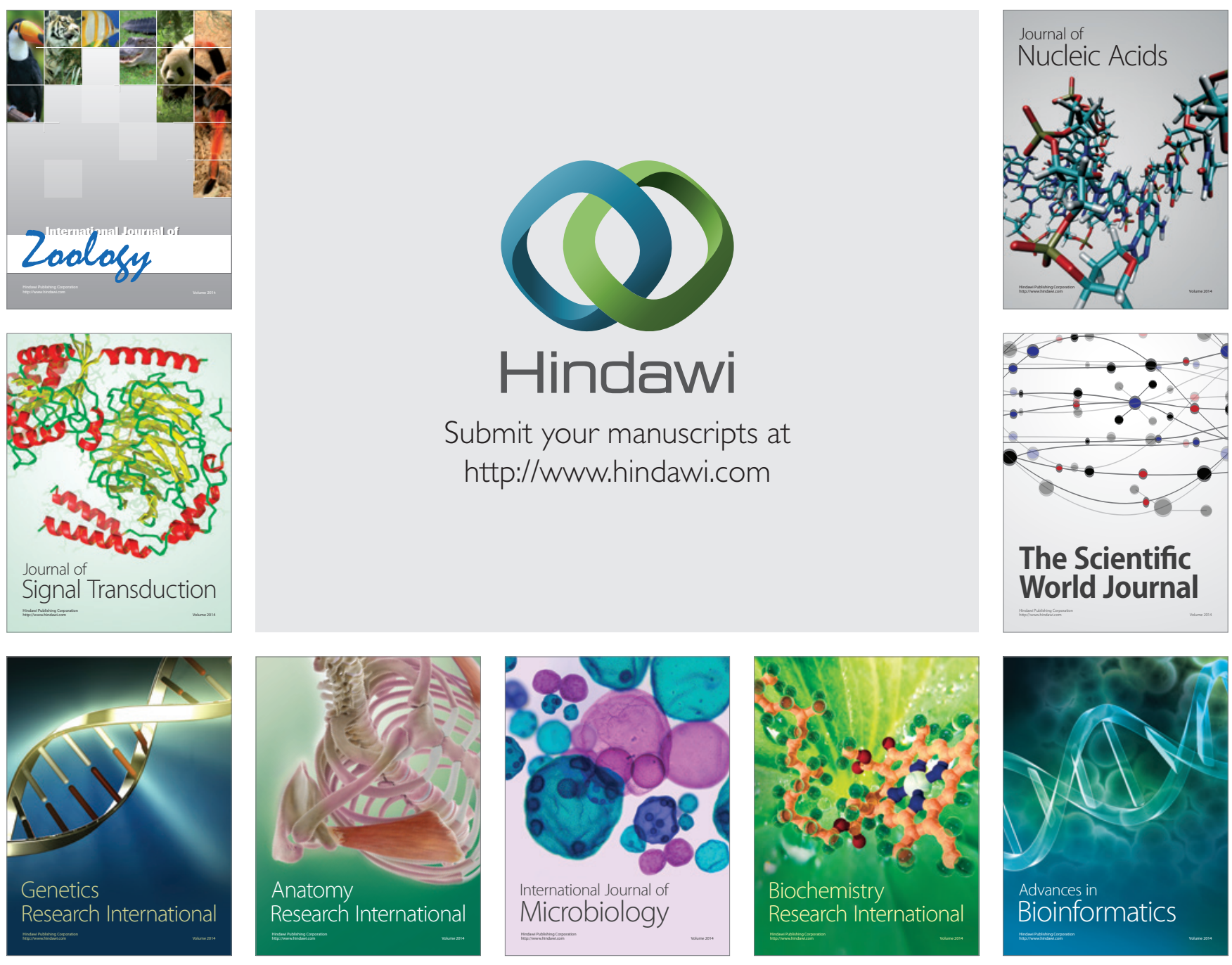

The Scientific World Journal
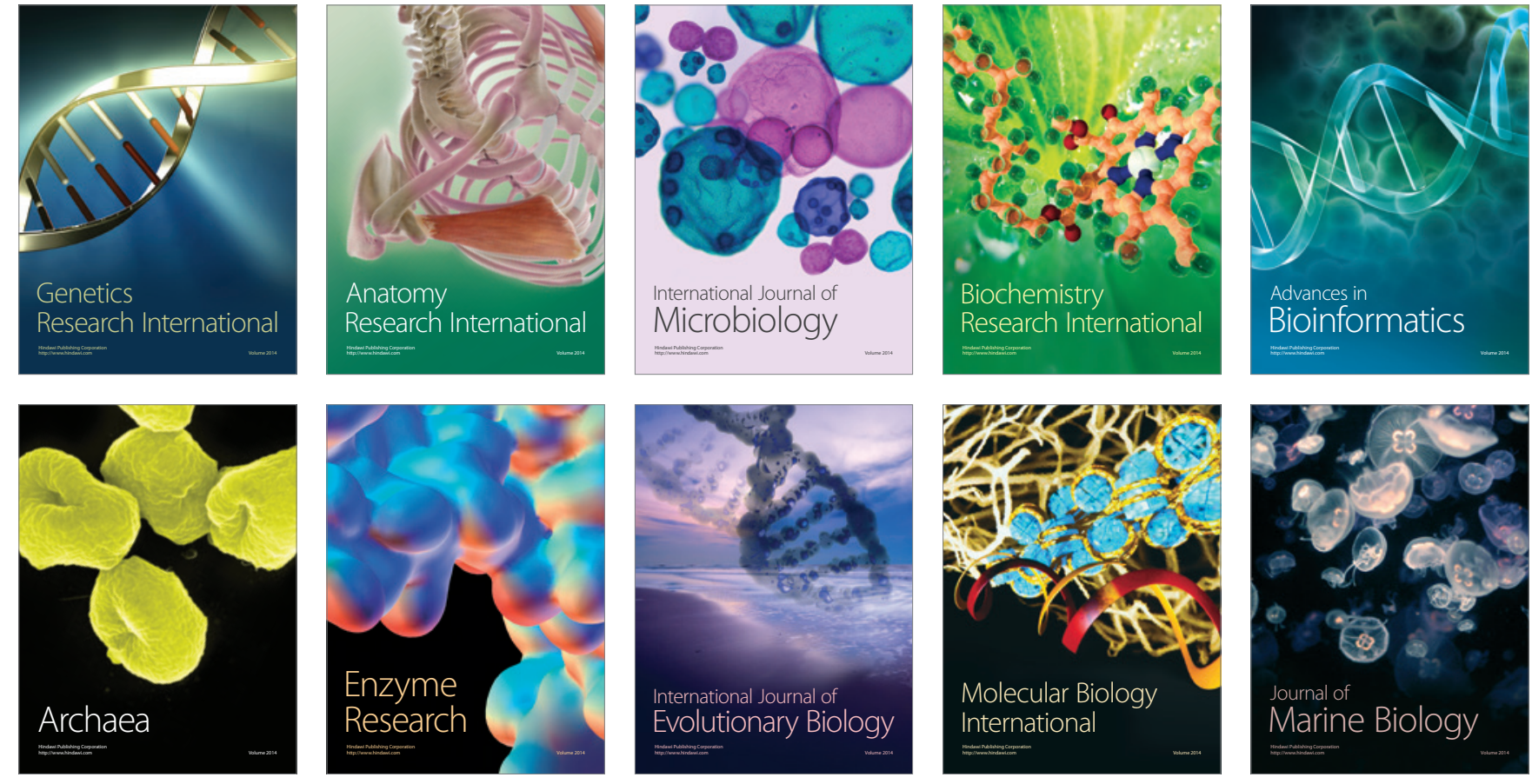